\title{
RNA Interference for the Treatment of Papillomavirus Disease
}

\author{
Richa Singhania $^{1, \S}$, Norliana Khairuddin ${ }^{2, \S}$, Daniel Clarke ${ }^{3, \S}$ and Nigel A.J. McMillan ${ }^{*} 3$ \\ ${ }^{1}$ The University of Queensland Diamantina Institute, Brisbane, Australia \\ ${ }^{2}$ Institute of Biological Sciences and Immunotherapeutics Laboratory, University of Malaya, Kuala Lumpur, Malaysia \\ ${ }^{3}$ School of Medical Science and Griffith Health Institute, Griffith University, Southport, Australia
}

\begin{abstract}
Human Papillomavirus (HPV)-induced diseases are a significant burden on our healthcare system and current therapies are not curative. Vaccination provides significant prophylactic protection but effective therapeutic treatments will still be required. RNA interference (RNAi) has great promise in providing highly specific therapies for all HPV diseases yet this promise has not been realised. Here we review the research into RNAi therapy for HPV in vitro and in vivo and examine the various targets and outcomes. We discuss the idea of using RNAi with current treatments and address delivery of RNAi, the major issue holding back clinical adoption. Finally, we present our view of a potential path to the clinic.
\end{abstract}

Keywords. Clinical trial, delivery, human papillomavirus, RNA interference, siRNA, shRNA.

\section{INTRODUCTION}

While the development of a prophylactic vaccine for human papillomavirus (HPV) infection is a tremendous advance in preventing disease, it is still clear that we have few therapeutic interventions that are effective, particularly in the setting of cervical cancer and laryngeal papillomatosis. Current therapy is highly invasive and we are still stuck in a "mediaeval torture" scenario whereby only physical intervention is available through laser ablation (burning), cryo-therapy (freezing), surgery (cutting), or chemical treatments (poisoning) including chemotherapy. While these remedies certainly achieve a level of effectiveness in terms of bulky reduction, no curative treatment exists and so improvements in terms of overall survival are needed. The search for a therapeutic vaccine has been ongoing for many years with no clinical success. It is clear that new approaches are required and this is where RNA interference (RNAi) may offer exciting new possibilities. While RNAi has the ability to act as a direct anti-viral, via the targeting of HPV sequences, it is also useful as a tool to rapidly identify novel anti-viral drug targets via large-scale screens. Since its discovery, the importance of RNAi in the viral setting has been quickly recognised, with human immunodeficiency virus (HIV) being one of the first targets where RNAi was shown to work [1]. Given the complete reliance of HPV on the expression of the oncogenes E6 and E7 for cancer formation, and in a form generally expressed off the same mRNA, HPV makes an ideal candidate for RNAi therapy and many groups have examined this possibility.

\footnotetext{
*Address correspondence to this author at the School of Medical Science and Griffith Health Institute, Griffith University, Southport, Australia; Tel: +61 7555271 35; Fax: + 617555289 08;

E-mail: n.mcmillan@griffith.edu.au

${ }^{\S}$ Equal contributions
}

Furthermore, while RNAi has the ability to act as a direct anti-viral via the specific targeting of HPV sequences, it is also useful as a tool to rapidly identify novel anti-viral drug targets via large-scale screens, and this could contribute to potential therapies. In this review we will outline past efforts of RNAi therapy for HPV in vitro and in vivo, examine the various targets and outcomes, as well as look at combined treatments, the issue of delivery, and finally offer our view on a potential path to the clinic.

\section{RNAi - A BRIEF OVERVIEW}

RNAi is an evolutionarily conserved gene silencing phenomenon that is orchestrated in cells by means of short non-coding RNAs, typically 20-30 nucleotides long [2]. The first reports of gene suppression came from the plant kingdom [3], but soon similar observations were made in a wide variety of eukaryotes. However, RNAi really came to the fore after the seminal discovery by Fire and Mello in $C$. elegans, where the expression of target mRNA was shown to be blocked by introducing sequence-specific short interfering RNAs (siRNAs) into the cell [4]. Typically, siRNAs are 21 nucleotides long, of which 19 nucleotides form a duplex and 2 nucleotides remain unpaired on each of the 3' ends [5]. This basic Tuschl siRNA structure can also be chemically modified to enhance its functionality and pharmacokinetic properties [6]. The findings by Elbashir and colleagues demonstrating that siRNAs could work in mammalian cells opened a new area of biology and suggested RNAi could be developed as a potential therapeutic [7].

The RNAi pathway (Fig. 1) is triggered in the cytoplasm when the RNase III endonuclease, Dicer, processes long double-stranded RNA (dsRNA) precursors or short hairpin RNAs (shRNAs) into effector siRNAs. Otherwise, 21-mer siRNA molecules mimicking Dicer cleavage products can be utilised to mediate RNAi effects. Subsequently, the antisense strand (complementary to the target mRNA) of the siRNA 
duplex is assembled into the multi-protein RNA-induced silencing complex (RISC) [8], commonly referred to as siRISC. The target-specific siRISC then base-pairs with homologous mRNAs, where the Argonaute-2 (Ago2) protein mediates mRNA slicing at a point 10 nucleotides away from the 5' end of the siRNA, resulting in the endonucleolytic mRNA cleavage [9]. Ultimately, the cleaved mRNAs become degraded by the action of cellular exoribonucleases and the catalytic siRISC is recycled to mediate multiple rounds of silencing. For extended gene silencing effects, siRNAs can be stably expressed from an expression vector in the form of shRNAs. The stem-loop bearing shRNA is exported out of the nucleus to be subjected to the nuclease activity of Dicer and the resulting siRNA is fed into the RNAi machinery to cause mRNA knockdown. It is this knockdown mechanism that can be exploited to reduce the levels of pivotal proteins involved in viral replication and disease.

\section{THE CONCEPT OF RNAi FOR HPV}

HPV infection was identified to be the major risk factor for cervical cancer almost 30 years ago $[10,11]$ with HPV types 16 and 18 , belonging to the high-risk group, causing approximately $50 \%$ and $20 \%$ cervical cancer cases respectively [12]. In addition to cervical cancer, HPV genotypes are also involved in other malignancies such as vulvar, anal, penile and oropharyngeal carcinomas $[13,14]$. Most HPV infections are naturally cleared or suppressed by cellular immunity but can sometimes cause benign hyperplasia with low malignant potential, or occasionally give rise to pre-cancerous lesions, which if not treated can eventually develop malignant phenotypes $[15,16]$. The diversity of HPV types, the lack of inflammation, and the generally unobtrusive nature of HPV infection all result in the immune system taking many months to recognise and clear infection. This, together with antigen differences between HPV types, has made development of treatments involving antigen recognition difficult. Indeed, therapeutic vaccines have proven unsuccessful to date. We do, however, have two successful prophylatic vaccines that are highly effective but it will take many years for the incidence rates of cervical cancer to be affected, highlighting the need for the development of therapies for those currently afflicted with $\mathrm{HPV}$-associated disease.

In terms of RNAi therapies any viral gene could potentially be targeted; this includes the six early nonstructural genes (E1, E2, E4, E5, E6, and E7) and the two late structural genes (L1 and L2) [17]. As the simultaneous

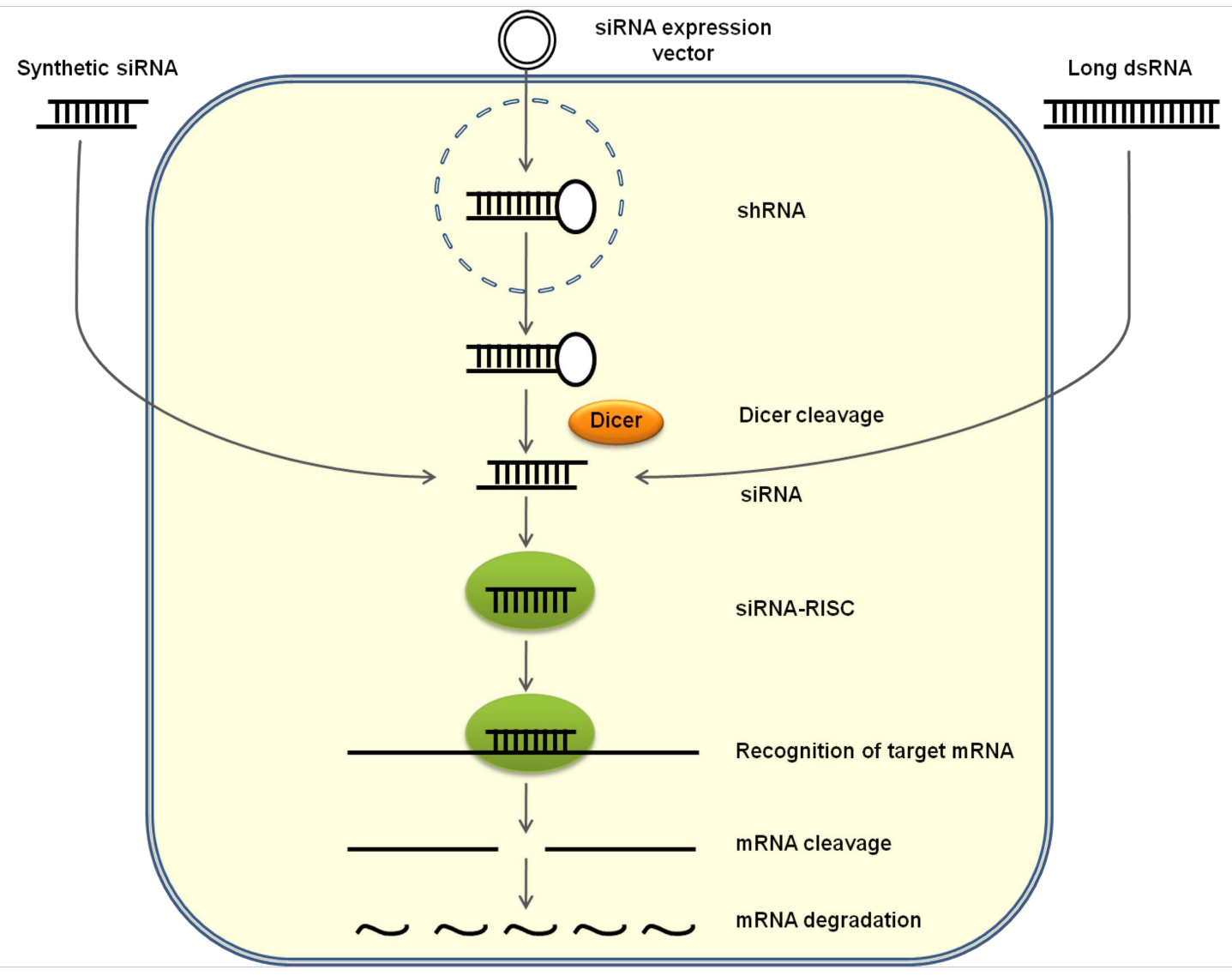

Fig. (1). Schema of the RNAi pathway. Schematic representation of siRNA-mediated RNAi pathway (Degradation pathway). Chemically synthesised effector siRNAs can be directly delivered into the cell or else generated from the cleavage of longer double-stranded RNA (dsRNA) and/or intracellularly expressed short-hairpin RNA (shRNA) by the endonuclease, Dicer. The antisense or guide strand is loaded into the RISC to form the activated siRNA-RISC complex (siRISC), which associates with the target mRNA bearing complementarity to the guide siRNA. Finally, Argonaute 2 protein (Ago2), the core component of siRISC mediates cleavage of the transcript in the base-paired region. The cleaved mRNA is released and the RISC components are recycled to mediate further rounds of silencing. 
expression of E6 and E7 oncogenes is pivotal for transformation and maintenance of malignant phenotypes [18] these genes have been the main focus by all goups to date. This complete reliance of E6/E7 expression and the fact that these genes are expressed from the same promoter and mRNA make these targets highly attractive. Hovewer, some complications have been noted. The sequence homology between the E6 and E7 genes of various HPV types is variable, meaning that each virus could potentially require a specific siRNA. Further, splice variants also exist, particularly in E6 expression, meaning target site selection is important [19]. Nonetheless, various groups have shown success in reducing the expression of both genes using a single siRNA (see below). The potential of E1, E2 and E4 have not been explored to date and there is only a single report investigating E5 [20]. As late genes are not expressed in HPV-induced cancers they would not make good anticancer targets.

Compared to other therapies RNAi has the advantage of being therapeutic, highly specific, and able to target all HPV types while exhibiting few side effects. It overcomes the major issue of non-specific toxicity to bystander cells exhibited by chemo- and radiotherapy and unlike current vaccines can be used in both a prophylactic and therapeutic setting. A comparison of siRNA to current treatments is presented in Table $\mathbf{1 .}$

Table 1. Comparison of siRNA with Current Treatments

\begin{tabular}{|c|c|c|c|}
\hline & siRNA & Chemo/radiation & Vaccine \\
\hline \hline Target & All HPV Genes & All cells & L1, L2 \\
\hline Prophylactic & $\checkmark$ & $x$ & $\checkmark$ \\
\hline Therapeutic & $\checkmark$ & $\checkmark$ & $x$ \\
\hline Long-lasting & $x$ & $x$ & $\checkmark$ \\
\hline Specificity & High & Low & High \\
\hline HPV types & All & All & $2-4$ \\
\hline Warts & $\checkmark$ & $x$ & $\checkmark$ \\
\hline CIN/AIN/VIN & $\checkmark$ & $\checkmark$ & $\checkmark$ \\
\hline $\begin{array}{c}\text { Laryngeal } \\
\text { Papillomatosis }\end{array}$ & $\checkmark$ & $\checkmark$ & $\checkmark$ \\
\hline
\end{tabular}

SiRNA therapies show major advantages over other forms of treatment including specificity, broad application and reduced toxicity. CIN, cervical intraepithelial neoplasia; AIN, anal intraepithelial neoplasia; VIN, vulval intraepithelial neoplasia.

\section{RNAi TARGETING HPV - A HISTORY}

While siRNA-induced RNAi can generally be utilised against any papillomavirus infection, published works have focused on the high risk, cervical cancer-inducing types HPV 16 and 18 (see Fig. 2). Jiang and Milner reported the first successful attempt at HPV silencing using siRNAs in 2002 [21]. SiRNAs designed selectively against either HPV16 E6 or E7 were delivered using lipid-mediated transfection reagents into the cervical cancer cell lines Caski and SiHa. A marked decrease in HPV 16 E6 or E7 mRNA was shown, representing selective knockdown due to specific siRNA directed against either gene. While both E6 and E7 knockdown showed an increase in cellular p53 following RNAi, knockdown of E6 was shown to reduce cell growth while knockdown of E7 induced apoptosis. This led to the conclusion by Jiang and Milner that knockdown of E7 rather than E6 would be better for therapeutic applications. It was also suggested in this study that specific targeting of the E7 protein could occur via RNAi without affecting E6 levels. However, as E6/E7 exists as a bicistronic open reading frame and is transcribed from the same promoter [22, 23], this claim was controversial.

Following Jiang and Milner's findings, Butz et al. demonstrated the effects of RNAi on HPV18 E6 alone over E7 [24]. This selectivity was achieved by designing siRNAs against the splice region of the E6 mRNA, which is not present in the majority of the transcripts expressing E7. It is worth noting that these siRNAs were delivered using a pSUPER vector system as opposed to liposome-mediated vectors previously preferred by Jiang and Milner. Targeting the splice region meant translation could still be initiated following intronic splicing, and E7 protein levels would not be affected following RNAi. They showed that E6 silencing alone resulted in apoptotic cell death of papillomaviruspositive cells and thus suggested the preference of E6 silencing for therapeutic approaches in contrast to the initial findings by Jiang and Milner. Yamato et al. further supported this theory by using siRNAs targeted against the regions outside of and within the E6 splice region, with siRNA directed against the spliced region showing a greater rate of cell death in HeLa and SW756 cell lines [25].

Several reports examining knockdown of both E6 and E7 proteins followed, using either E6- or E7-directed siRNA treatment [26, 27]. These showed that delivery of siRNAs against E6 or E7 would induce cell senescence in the absence of apoptosis. While the debate of cell fate following RNAi is still ongoing, all reports agreed on reduced cell number and growth in vitro following RNAi treatment [21, 24-26].

These initial in vitro findings were followed by in vivo experiments. These typically involved the inoculation of cervical cancer cells pre-treated with E6/E7 siRNAs in immune-deficient mice and generally reported reduced tumour growth compared to those treated with control siRNAs (reviewed in [28]). Similarly, pre-treatment of murine TC-1 cells with HPV16 E7 siRNAs also resulted in smaller tumours in immune-competent mice [29]. Even more promising was permanent HPV18 E6/E7 shRNA transfection which used lentiviral vectors to deliver into mice, as this was shown to result in complete loss of tumour growth [30]. Niu et al. then demonstrated that intratumoural injections of siRNAs could lead to tumour suppression in Caski cells [31], while findings from our laboratory have shown that systemic delivery of siRNAs encapsulated in liposomes were able to selectively reduce TC-1 tumour growth in C57BL/6 mice $[29,32]$.

Overall, in both cells and pre-clinical animal models, published results using RNAi directed against HPV E6 and E7, whether as siRNA or shRNA, all point to treatment being extremely specific and highly potent. These results were encouraging in terms of progress towards the clinic but as outlined below, there are significant technical hurdles to overcome, particularly in the delivery area, before this becomes a reality. 


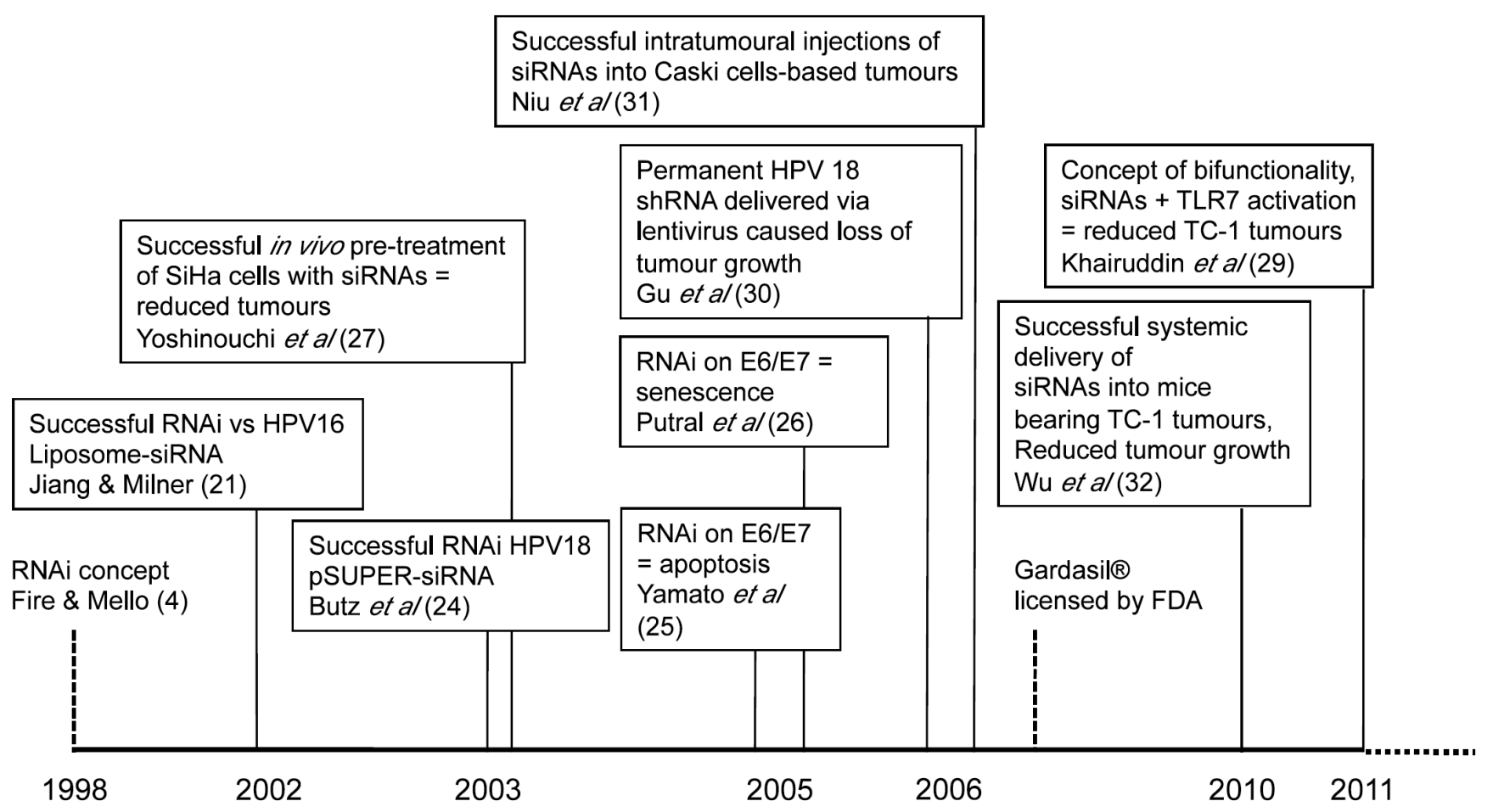

Fig. (2). A Timeline of HPV RNAi research. Studies into RNAi directed against high-risk papilloma types have facilitated significant progress towards a promising therapeutic since the first successful attempt at silencing E6/E7 in 2002.

\section{DOES RNAI INDUCE APOPTOSIS OR SENESCENCE?}

Due to the role of E6 and E7 in maintaining cell proliferation and immortalisation of infected cells, treatment with siRNAs lead to reduced cancer cell proliferation and clearance. Most published works as we have reviewed here agree that the downstream effects post-RNAi in HPVinfected cells achieve these outcomes, thus highlighting RNAi as a therapeutic strategy for HPV-induced diseases. However, the question of whether these cells undergo senescence or apoptosis post-RNAi is still open to debate.

HPV E6 maintains cancerous conditions through an antiapoptotic activity against p53 via ubiquitin-dependent proteolysis and proteasomal degradation [33]. The consequent knockdown of E6/E7 will result in a cellular accumulation of $\mathrm{p} 53$, a protein known to cause apoptosis [21]. However, reports by Putral et al. and Hall et al. provided evidence that siRNA transfection causes HPVinfected cells to undergo senescence rather than apoptosis in the presence of cellular p53, an intriguing result $[26,34]$.

To further elucidate this effect, DiMaio's group in Yale silenced E6 and E7 in HPV18-positive HeLa cells by expressing bovine papillomavirus (BPV) E2 protein, a natural viral suppressor of E6/E7, and tested for cellular senescence and colony formation [35]. They then expressed exogenous HPV type 16 E6 or E7 in these cells thus leading to specific repression of either E6 or E7 alone so that the role of each gene was able to be observed separately [36]. With E7 repressed, $\mathrm{pRb}$ was activated and triggered cell senescence, while E6 repression resulted in the activation of p53 and triggered both senescence and apoptosis. Interestingly, repression of either gene also inhibited telomerase activity, cyclin-dependent kinase (CDK) activity and expression of c-myc [35-37]. Thus, this allowed them to cleverly tease out the roles of E6 and E7.

These separate roles for E6 and E7 were also the focus of other publications. The most relevant role of E6 is to cause p53 degradation, avoiding apoptosis [33]. In the presence of E6, a complex of ubiquitin ligase E6-associated protein (E6AP) is formed [38], leading to an E6AP-directed, ubiquitin-mediated degradation of pro-apoptotic factors Bak/Bax [39, 40], which further halted apoptosis and allowed infected cells to proliferate. E6 also targeted proapoptotic factor MAG-I, affected Akt signalling and inhibited apoptosis [41]. E6 was further shown to exert effects at the cell cycle G1-S transition, alleviating G2 arrest imposed by anti-proliferative signals induced by $\mathrm{p} 16^{\mathrm{INK} 4 \mathrm{a}}$ and p2 $7^{(\mathrm{kip} 2)}$ [42], thus contributing to cell immortalisation and transformation. It is perhaps no surprise then that specific silencing of the E6 protein was able to abrogate these effects via reactivation of cellular p53 and cause infected cells to undergo both cellular senescence and apoptosis.

On the other hand, the most prominent role of E7 is to inactivate phosphorylated retinoblastoma protein $(\mathrm{pRb})$, allowing progression of virally-infected cells to $S$ phase where DNA replication occurs [43]. Binding of E7 to $p R b$ causes proteasomal degradation similar to the effects of E6bound $\mathrm{p} 53$ [44]. This degradation of $\mathrm{pRb}$ allows E2F to freely bind promoters of genes associated with cell cycle progression, resulting in increased cell replication [45]. Other cell cycle proteins affected by E7 binding and presence include the cyclin-dependent kinase inhibitors (CKIs) p21 and p27 [46] that allow the release of CDK/cyclin complex inhibition [46-48], CDK2 that enhances viral life cycle progression [49], and DNA methyltransferase 1 (DNMT1) that influences DNA 
methylation leading to genomic instability and aneuploidy [50], which is a hallmark of cellular malignant progression and cancer [51]. Thus, specifically silencing E7, if it were possible, would halt cell cycle and reactivate $\mathrm{pRb}$, causing cells to prominently undergo senescence.

One issue affecting this research has been the use of the qualitative and $\mathrm{pH}$-dependent senescence-associated $\beta$ galactosidase assay to measure senescence. It takes a long time to develop and is difficult to control with regard to $\mathrm{pH}$. Better assays would be useful to gain more reliable results, such as using molecular markers as opposed to this somewhat variable assay. For example, a microarray analysis on E6/E7 siRNA-transfected TC-1 cells showed induction of the Bcl2113 gene [52], a member of the Bcl2 family described to block apoptosis and lead cells into senescence [53]. Molecular-based assays to probe for senescence markers (p16 ${ }^{\mathrm{INK} 4 \mathrm{~A}}, \mathrm{CXCL} 14 / \mathrm{BRAK}$ and p311) [54] versus apoptosis assays such as TUNEL/Annexin V staining [55, 56], could also be carried out to directly compare siRNAtransfected cells and more reliably elucidate post-RNAi cell fate. Ultimately, whether the end result is senescence or apoptosis, the outcome from a therapeutic perspective is that cancer cells will no longer grow and will be removed by normal cellular turnover mechanisms.

\section{COMBINED THERAPIES- DRUGS}

Despite demonstrating much promise, RNAi has had limited success in the clinical setting, with the reported phase $1 / 2$ clinical trials showing modest effects to treat viral infection or macular degeneration (reviewed in [57]). This has been linked to either poor delivery and/or low siRNA efficacy. All cancer-specific trials in phase $1 / 2$ have yet to report outcomes and generally target common targets in solid tumours such as polo-like kinase 1 (PLK1), vascular endothelial growth factor (VEGF), etc. However, a common clinical strategy is to combine new treatments, such as RNAi, with standard care. In the case of HPV-mediated cancers, standard treatments are generally surgery, radiotherapy or chemotherapy (with the agents cisplatin, camptothecin, or bleomycin are currently approved in the USA). In vitro results have suggested this is a viable approach, with one study showing that by targeting HPV oncogenes using siRNA, the p53 pathway can be reactivated and lead to a four-fold increase in the sensitivity of tumour cells to cisplatin [26]. Therefore, this strategy could be used to reduce the cisplatin dose requirement, which is extremely important as the typical doses required to activate p53 in cervical cancer cells in the presence of HPV E6 often lead to drug resistance and detrimental side effects including neurotoxicity [58-60]. More recently, the combination of E6/E7-specific siRNA and cisplatin therapy was further confirmed to be significantly superior to either modality alone using a combination of both in vitro and in vivo experiments. The long-term exposure of HPV-positive cervical cancer cells to the combination of cisplatin and E6/E7-specific siRNA in vitro was shown to induce apoptosis and cellular senescence [61]. In addition, the combination of E6/E7-specific siRNA and either low-dose or high-dose cisplatin delayed tumor growth and induced tumor regression in a xenograft mouse model of cervical cancer via the induction of apoptosis, senescence and anti-angiogenesis [61].
Other than cisplatin, there has also been some success with other clinically relevant chemotherapeutic drugs when combined with RNAi therapy. For example, the restoration of the p53 pathway by degrading E6 mRNA has been shown in cytotoxicity assays to increase sensitivity to doxorubicin and gemcitabine [62], while combined application with paclitaxel can inhibit cervical tumour growth in mice [62, 63]. Another clinical therapy that has potential when used in tandem with siRNA against E6 is that of the targeted induction of apoptosis through the tumour necrosis factorrelated apoptosis inducing ligand (TRAIL). Cervical neoplasia specimens have been shown to express the death receptors DR4 and DR5, both of which are activated by TRAIL, and the expression of these receptors are upregulated upon re-instatement of the p53 pathway [64, 65]. Consequently, knockdown of E6/E7 through siRNA treatment may be able to prevent proteasomal degradation of p53 and lead to the transactivation of death receptor expression on the cell surface, sensitising these cells to TRAIL and leading to the induction of apoptosis. To date, the results have been mixed and this phenomenon has only been seen in E6-suppressed cells treated with cisplatin but not in cells treated with siRNA alone [66]. These in vitro effects on cultured cervical cancer cells may be due to the preferential induction of senescence, which could preclude the TRAIL-mediated activation of the apoptotic pathway [67].

Other rational approaches that promote restoration of $\mathrm{p} 53$ levels could also have some benefit when combined with RNAi therapies. Certain antibodies that bind to the NH2terminal region of E6 have been found to totally block the E6-mediated degradation of p53 in vitro [68] and these could be co-delivered with siRNA directed against E6 to have a synergistic effect [69]. Also, specific protease inhibitors such as lopinavir can inhibit the E6-mediated proteasomal degradation of p53 and when combined with RNAi could promote selective toxicity of HPV-transformed cervical carcinoma cells by increasing p53 levels and inducing apoptosis [70]. Lastly, CDK inhibitors, such as purine-based roscovitine, have been shown to prevent the initiation of transcription from viral genomes and this could be used in combination with siRNA to restore p53 levels, driving apoptosis in HPV-transformed cells [71, 72].

\section{COMBINED THERAPIES- IMMUNE SYSTEM}

A further potential for combining siRNA therapy is to involve the immune system in recognising and clearing HPV-infected cells. While all clinical trials testing siRNAs go to great lengths to avoid immune activation via modification of the phosphodiester backbone, the idea of using the immune system to aid in treatment is becoming recognised. After all, we know that curing HPV infections require both innate and adaptive immune responses and this has been the goal of immune-based therapies for some time. The combination of senescence and/or apoptosis combined immune system activation via siRNA-mediated activation of Toll-like receptors (TLRs) is an intriguing possibility. We know, for example, that interferon (IFN)- $\alpha$ was used in treating genital warts (condyloma acuminata) caused by HPV $[73,74]$ and siRNA has been shown to induce IFN via TLRs [75]. Moreover, Aldara ${ }^{\circledR}$, a potent TLR7 agonist, has been licensed to treat HPV-induced genital warts. Thus, a 
combinatorial approach of RNAi plus TLR-activating activity may result in an improved anti-viral, anti-tumour strategy against HPV-induced disease.

SiRNAs are activators of TLRs and other modulators (see Fig. 3), which results in the triggering of innate immune activation [75]. Protein kinase R RNA-dependent protein kinase (PKR), retinoic acid inducible gene-I (RIGI)/interferon-induced helicase domain C (MDA-5) and TLR7 are all examples of innate immunomodulatory receptors that are all activated by siRNAs. The induction of PKR by small RNAs is well documented, although siRNAs have been shown to be poor inducers in vivo [76]. Induction of PKR by siRNA activates the downstream proteins nuclear factor of light polypeptide gene enhancer in B cells $(\mathrm{NF \kappa B})$ and interferon regulatory factor 1 (IRF-1), further activating signal transducer and activator of transcription 1 (STAT-1) [77-79]. Phosphorylated STAT-1 with IFN regulatory factor 7 (IRF7) acts as a transcription factor to induce the expression of IFN $\alpha / \beta$ genes, producing the release of these cytokines by siRNA-transfected cells. Addition of structural modifications to siRNAs, in particular 5'-triphosphate, have been shown to also trigger specific recognition by RIGI/MDA-5 [80]. Activation of RIG-I leads to the downstream activation of IRF3 and further induction of type 1 IFNs including IFN $\alpha / \beta$ [81]. Together, the induction of PKR/RIGI/MDA-5 can promote an anti-viral defence status in epidermal keratinocytes [82] and this may be a useful tool in a combined RNAi therapy.

Another important observation is that liposomeencapsulated siRNAs have been described to accumulate in cellular endosomes, exposing siRNAs to recognition by endosomal TLRs, particularly TLR3 and TLR7 [83]. This activation would promote ligand binding and dimerisation of separate immunomodulators; toll/interleukin-1 receptor homology domain containing adaptor protein inducing IFN $\beta$ (TRIF) for TLR3 and myeloid differentiation primary response protein 88 (myD88) for TLR7 [84]. Engagement of these adaptors can then activate mitogen-activated protein (MAP) kinases and $\mathrm{NF \kappa B}$ [85], inducing a cellular inflammatory response. Similarly, sequence-specific sensing by TLR7 of uridine-bulge siRNAs or siRNAs with high-U sequence motifs would activate IRF7 via interleukin-1 receptor-associated kinase (IRAK1) and IRAK4, activating transcription and consequent secretion of IFN $\alpha / \beta[86,87]$. On the other hand, siRNA recognition of TLR3 induces a

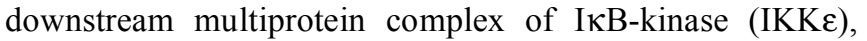
tumour necrosis factor (TNF) receptor associated factor-3 (TRAF3), and TANK-binding kinase 1 (TBK1) [87]. This complex then activates IRF3, which acts similarly to IRF7, driving IFN activation. IRF3 is also triggered by RIG-I through the IPS-1/PKR/RIG-I pathway presenting a further mechanism of IFN activation. [88].

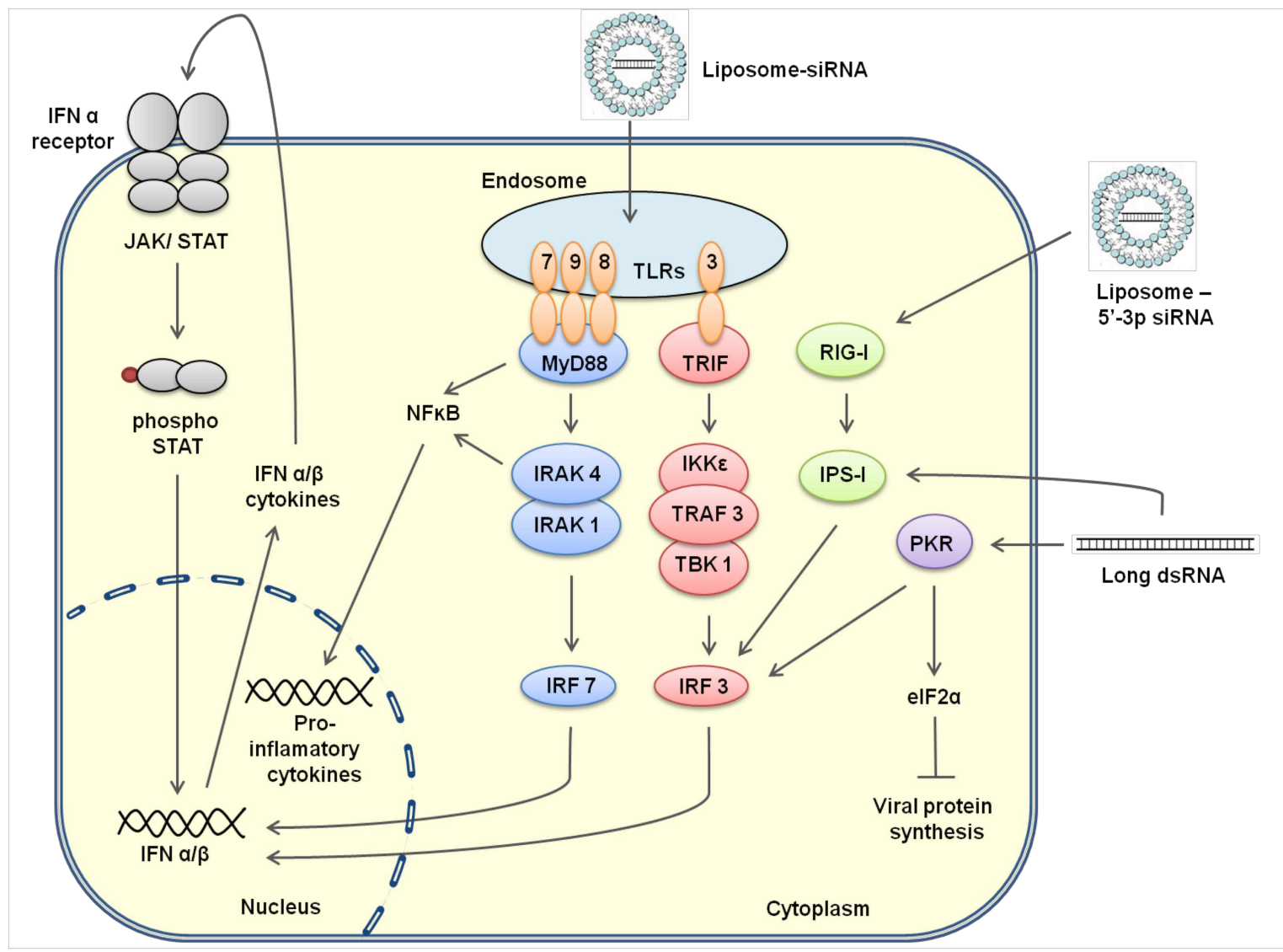

Fig. (3). Schema of Immune activation by siRNAs. RNA oligonucleotides and siRNAs are potent stimulators of the innate immune system, exerting their effects by activating endosomal toll-like receptors (TLRs), or the immunomodulatory proteins retinoic acid inducible gene (RIG)-I or Protein kinase R RNA-dependent protein kinase (PKR). This leads to the induction of interferon (IFN) and pro-inflammatory cytokines to promote an anti-viral state, which could be beneficial in a combined therapy against HPV disease. 
Taken together, siRNA-induced immunostimulation causes elevated levels of type I IFNs, bridging the innate with the adaptive immune response and further acting as immunomodulators through the action of natural killer (NK) cells, dendritic cells (DCs), and macrophages [89, 90]. This induction of type I IFNs via TLR7-sequence specific sensing is obviously important as it is conserved in both human and mouse [91-94]. It has also been shown that an elevated level of TNF $\alpha$ is as good an indicator of immunostimulation as IFN $\alpha[95,96]$ and this is important as the activation of TLR7 also activates the NFKB pathway, leading to induction of TNF $\alpha[97]$.

It is important to note that siRNA sensing by pattern recognition receptors (PRRs) is influenced by siRNA structure or sequence motifs and by exploring these features it could lead to promising cancer therapeutic applications. Addition of ligands such as CpG-DNA to siRNAs have been shown to activate TLR9, with bifunctionality shown to be more effective at reducing melanoma in vivo than RNAi effects alone [98]. Other motifs have also shown promise in the cancer therapeutic setting such as the 5'-triphosphate, which when combined with siRNA (3p-siRNA) activates RIG-I [80], as does the addition of a uridine bulge to the siRNA backbone [99]. Furthermore, siRNAs with sequence motifs such as UGUGU are biased towards immunostimulation and PRR sensing, more so than siRNAs devoid of such sequence motif [100]. This bifunctional approach demonstrates gene knockdown coupled with the added benefit of immunostimulation is a useful and novel approach to therapy.

Successes of this type have already been noted with bifunctionality leading to the improved efficiency of siRNAs as a therapy against HPV-induced disease [29]. Activation of TLRs inducing IFNs has been seen as a proven anti-tumour strategy [101] via the enhancement of innate immunity, activation of $\mathrm{T}$ cell immunity and an increased response to cytotoxic T cells (CTL). Stimulation through TLRs also enhances cytotoxic killing and induction of apoptosis in TLR positive tumours. A successful example of TLR-activation for therapeutic potential is the use of the TLR agonist Aldara $^{\circledR}$ (Imiquimod), which has been used to treat genital warts caused by HPV [102]. Topical application was found to augment $\mathrm{T}$-cell responses and enhance representation of CTLs in monocyte dendritic DCs (mDCs) [103]. This further promoted maturation of E7-loaded $\mathrm{mDCs}$, which included E7-specific $\mathrm{T}$ cell responses characterised by elevated expression of IL-12 and IFN $\gamma$ secretion by CD4 naïve Tcells. Meanwhile, the TLR agonists, isatoribine and resiquimod, induce IFN $\alpha$ through TLR7/8 activation and have been shown to cause the reduction of Hepatitis $\mathrm{C}$ virus [104]. These immunological responses by TLRs allow assistance in tumour cell clearance once these cells are targeted by degradation and reinforce the concept that a bifunctional siRNA approach could provide a promising single molecule approach for HPV-induced disease.

There are compelling reasons to use RNAi in combination with conventional drugs and/or the immune system. The former marks an easier road to clinical trials as it just involves adding siRNA to current standard-of-care practises and is likely to yield results based on promising preclinical data. The latter represents a more speculative approach which recognises that the immune system is ultimately involved in all "cures" and finding ways to manipulate it for better cancer outcomes has been the focus of much research over many years. Using siRNA with immune activating properties extends this approach but there is clearly a need for caution in order to avoid overt inflammatory responses. While combined therapies will potentially improve efficacy, there still remains the issue of how to deliver siRNAs to target cells.

\section{THE DELIVERY OF RNAi}

A major barrier to the success of RNAi therapy has been the vexing issue of delivery. SiRNAs on their own are inherently unstable in bodily fluids and poorly taken up into cells due to their size, charge, susceptibility to nuclease attack, and short half-life caused by renal clearance and aggregation through interactions with proteins such as serum albumin [105]. These obstacles can be reduced by incorporating siRNAs into particles, complexes, or by applying chemical modification to the RNA backbone. Indeed, the introduction of phosphorothioate and 2'-Omethyl sugar residues into the siRNA backbone has been shown to reduce degradation by exo- and endonucleases in serum and tissues [106]. However, even modified, naked siRNAs have poor cellular uptake due to their small size, net negative charge, renal clearance, and hydrophilicity [107]. Therefore a range of delivery vectors such as liposomes, polymers and nanoparticles have been developed to facilitate cellular absorption as well as provide a degree of protection.

Clearly for RNAi therapy to be effective there is a need for delivery systems that work at the major sites of HPV infection. This includes the mucosal surfaces of the vagina and cervix, the anus, the larynx and the oral cavity, as well as cutaneous skin. The ability to deliver to these localised areas rather than systemically is advantageous as it bypasses firstpass hepatic and kidney clearance, enables targeted local delivery to the infected tissue, potentially reduces the required doses and achieves higher local concentrations of siRNA. While localised mucosal delivery has its own set of challenges, successful delivery of siRNA to the vaginal tract holds great potential for the treatment of other viral infections such as HIV and Herpes simplex virus (HSV) (reviewed in [108]). In the vaginal setting, siRNA molecules must be able to resist rapid degradation by nucleases and inactivation by the low $\mathrm{pH}$ of the vaginal environment, as well as be able to bypass the top layer of dead, hyperkeratotic cell entrapment in the mucosal layer. Additionally, they must be formulated so that they remain available for cellular uptake by cells targeted by the virus. Essentially though, the main barrier for efficient vaginal siRNA delivery is the mucosal layer. It is a protective barrier for underlying tissues and removes foreign particles efficiently [109], thus complicating sustained release. Another important factor to consider that may dramatically affect the efficiency of delivery in the vaginal cavity is the physical environmental changes that occur throughout the estrous cycle [110].

To date, several groups have reported varying success in delivering siRNA to the vaginal tract. Previous strategies to overcome vaginal delivery barriers have included the simple application of lipoplexes into the vaginal cavity either with $[111,112]$ or without [113] progesterone treatment, as well 
as mucus removal in the vaginal cavity prior to siRNA administration [114]. Unsurprisingly, investigations of naked siRNA uptake into vaginal tissues after intravaginal administration reported inefficient delivery [113] under normal physiological conditions. This was likely caused by rapid degradation and inefficient mucosal uptake of naked siRNAs in the vaginal cavity. However the same study showed dramatically improved delivery with the use of the cationic transfection reagent Lipofectamine ${ }^{\circledR}$. In contrast to this report, we have found that conventional lipoplexes are not able to reach the cervicovaginal epithelium and are not retained in the vaginal cavity following administration under normal physiological conditions [115].

Progesterone has been used prior to treatment in multiple studies to arrest mice in the diestrus phase of the estrous cycle. Initial studies that used this method investigated vaginal instillation of siRNAs targeting HSV-2 in a lipid formulation. Palliser and colleagues reported that siRNAs mixed with Oligofectamine ${ }^{\circledR}$ resulted in efficient delivery to the epithelial and lamina propria cells and protected mice from lethal HSV-2 infection [111]. However, this was marred by further investigations into cationic lipidic systems for intravaginal delivery that raised concerns regarding their safety in vivo. Wu and colleagues reported that inflammation occurred in vaginal tissues following administration of the cationic lipidic transfecting reagent Oligofectamine ${ }^{\circledR}$ [112]. Furthermore, they found that the transfection lipid on its own enhanced transmission of HSV-2. Prevention and protection from HSV-2 was instead obtained by a cholesterolconjugated siRNA that caused virus gene silencing in the vaginal tract without inflammation or cytokine induction. However, progesterone pre-treatment in mice is typically associated with thinned vaginal epithelia that may facilitate epithelial penetration, and is dissimilar to any human estrous phase [116]. Progesterone use has additionally been associated with increased susceptibility and decreased immune responses to vaginal infections [117, 118].

Another strategy of evaluating siRNA silencing in the vaginal tract has used manual removal of the mucus layer [114]. This study also provided an alternative to siRNA lipoplexes with the use of biodegradable polymer-based poly(lactic-co-glycolic acid) PLGA nanoparticles. A single dose of siRNA-loaded nanoparticles resulted in efficient and sustained gene silencing from the proximal vaginal lumen to the distal uterine horns. This work has yet to be repeated by others but could be a promising approach.

One other important consideration for delivery is the sustained application of the RNAi as it has been found that retention time is a major issue to achieving sustained vaginal silencing. We have developed a biodegradable matrix that works to solve this problem called the PEGylated Lipoplexentrapped Alginate Scaffold (PLAS) [32, 115]. This sustained release system is based on the entrapment of muco-inert polyethylene glycol or PEG-lipoplexes in a biodegradable scaffold of alginate. It provides continuous release of siRNA in the vaginal cavity over at least 24 hours and the use of PEG enhances particle stability in the presence of mucin [119]. We chose alginate, as it is a naturally occurring polysaccharide already approved by the FDA for various uses including incorporation into food products and wound dressings. It is also readily cross-linked by divalent cations such as calcium to form a solid matrix without the use of organic solvents [120, 121]. Scaffolds made from alginate readily decompose in the presence of sodium ions, which are naturally occurring within the body, and thus serve as a trigger to release entrapped therapeutics slowly over time [122].

A further advantage of this method is a solid vaginal siRNA delivery system with the ability to be retained in the vaginal cavity following administration without prolonged anaesthesia and the capability to be administered at any stage during the estrous cycle. Consequently, this system can be easily adapted for clinical use to deliver siRNA that is retained in the vaginal cavity after administration and achieve efficient delivery to the cervicovaginal epithelium under normal physiological conditions. When inserted intravaginally we found that PLAS offered a 6-fold increase in siRNA delivery compared to cationic lipoplexes. More importantly we were able to achieve $85 \%$ knockdown of lamin A/C in vaginal epithelial cells using PLAS [115].

Other areas of local HPV infection could also be considered when developing these strategies. The delivery of siRNAs to the anal region should be possible with PLAS. In the case of skin, degradable solid nanoparticles, direct injection and microneedle-based delivery have all been demonstrated to work [123-126], while high-density nanoneedle projections also have been suggested as a possible solution. The larynx, for the treatment of laryngeal papillomatosis, is a more challenging location and to date there have been no reported studies. One could envisage a nanoparticle-based spray that might be useful but it would require repeated doses, as the retention time would be particularly poor in this location. A gel might solve this but would be difficult to deliver unless perhaps applied at the time of surgery. Finally, HPV is associated with oral cancers and delivery of HPV-specific siRNAs in the mouth area offers much the same challenges as vaginal delivery. Once again no studies have come to light, which further highlights delivery as the most pressing obstacle to therapy.

\section{USING RNAi TO IDENTIFY NOVEL DRUG TARGETS IN CERVICAL CANCER}

RNAi technology has another potential use that could contribute to a HPV therapy. This is its application in the discovery of novel drug targets required for viral replication and disease progression. By undertaking genome-wide RNAi screens in infected and control cells, one can uncover genes that affect only virally-infected cells or indeed cancers resulting from HPV infection. There are two commonly used approaches for RNAi screening that utilise either synthetic siRNA libraries (via liposome-mediated transduction) or shRNA (via lentiviral transduction). The concept of the screen is simple - normal and cancer cells are transfected in parallel with siRNA/shRNA and each well is then examined for loss of viability or cell death. Ideally virally-infected or cancer cells would die while normal cells are unaffected, thus identifying so called synthetic lethality genes. These are genes required by the cancer cell but whose loss can be tolerated in normal cells and therefore are novel targets for drug intervention or RNAi therapy.

In the case of HPV, only a small number of screens have been reported. The Harlow and Munger labs undertook a 
kinome screen using shRNAs and discovered 26 kinases that were required in all three HPV cell lines tested [127-129]. They used these screens to identify HPV E7 target kinases (e.g. CDK6, ERBB3, FYN, AAK1 and TSSK2) as well as finding that the kinases SGK2 and PAK3 were synthetic lethal in HPV cells. These kinases represent a new class of HPV-specific targets against which therapies can be developed. Another study undertook a larger, genome-wide screen to identify genes that suppress expression from the HPV18-long control region (LCR) [130]. Examining more than 21,000 genes, the primary screen confirmed 96 cellular genes that are essential in the suppression of the HPV18LCR. As expected, most of these genes primarily worked together with E2 however, some acted independently to repress the LCR. Besides the identification of novel targets this study also supported the hypothesis that E2 engages different cellular pathways to down-regulate the expression of the oncogenic activities of HPV18.

RNAi screens have been used for a number of viral infections such as HIV, Influenza virus, HCV, Dengue virus, and West Nile virus (reviewed in [131]). From these a number of novel targets have been identified and are the subject of intense research and development. One surprising issue that has arisen from these screens has been the lack of overlap between the genes identified in each study. Subsequent meta-analysis suggests they do identify genes within similar pathways and the differences can be attributed to experimental noise, differences in sampling time, and variations in hit selection criteria. No doubt many more such screens will be reported in the near future and this technology promises to not only result in a number of new approaches to the treatment of cervical cancer, but also for a range of other cancers and viral infections. These targets may be amendable to siRNA therapy or to small molecule inhibitors, many of which may already have been developed for other indications.

\section{THE PATH TO THE CLINIC AND TRIAL DESIGN}

In thinking about a potential clinical trial design for siRNA to treat HPV disease, a number of factors need to be considered, the first of which is to determine the particular disease to target (cervical intraepithelial neoplasia (CIN)-1, CIN-IV, warts, genital warts, etc.). Our suggestion is that the greatest need at present for therapeutic intervention is in the cervical cancer area. Moreover, the current treatment for low grade CIN-1 is a wait-and-see approach. This lends itself to a potential trial during the waiting period while still allowing researchers to keep current treatment as best practice. Any HPV-specific siRNA should function to target E6 or E7, as these genes are absolutely required for cell survival. While a phase 1 safety trial would be required, we present a simple phase 2 trial that would give a strong indication of potential success. We would suggest a doubleblind, 2 arm (treatment and placebo), 40 patient trial of patients presenting with abnormal papinicolaou (Pap) smears. Patients would be $18-30$, not be pregnant or likely to get pregnant and generally healthy. At entry, a biopsy would be taken and the HPV DNA status determined. Then treatment would then be given in the form of a physician applied patch, gel or liquid (depending on formulation). At one month, examination of the area and associated biopsy would confirm any resolution and/or loss of HPV. This would be a small, low-cost trial to gain insight as to the potential for an siRNA-based therapy. For advanced metastatic disease, systemic delivery is obviously required. At the present time the best option is lipoplexes based on stable nucleic acid lipid particles (SNALP)[132]. Such particles have been effective in several clinical trials to date [57]. Once again E6/E7 would be the target in this treatment. One issue with such particles is the reliance on non-specific delivery and so a research priority would be to identify targeting ligands for cervical cancer cells. At present a popular ligand is the folate receptor, which is generally overexpressed in cancers but other ligands also need to be developed. It is in advanced disease that combined therapies will be tested. The likely best path forward would be in the use of siRNA-lipoplexes with current chemotherapy as a first step as this would be more likely to achieve a desired outcome. Finally, until compelling preclinical animal model data comes forth the concept of immune-activating siRNAs is unlikely to proceed to the clinic.

\section{CONCLUSION}

Much work has been undertaken in both in vitro culture and small animal experiments to show that siRNAs against HPV are highly effective at reducing cell growth and tumour size. As no satisfactory animal model of cervical cancer exists other than E6/E7 transgenic mice, the next logical step is small-scale human trials. Like much of the siRNA field, this is being held back by poor delivery systems although a number of vaginal delivery systems, including the PLAS system, offer a potential solution. For local skin delivery the new micro- and nanoneedle technologies look promising. While E6 and E7 are the obvious targets of choice, other targets such as E2 and E5 might be useful but have not been explored much to date. Perhaps combinations of siRNAs targeting all 4 genes may prove even more potent. We also note that very little has been done to explore radiation therapy in combination with siRNA and this might also prove to be a promising approach. Finally, given the high specificity of RNAi for HPV genes, cervical cancer would be a good target for more permanent treatment via DNAdirected RNAi and lead to improved outcomes in the future.

\section{CONFLICT OF INTEREST}

The authors confirm that this article content has no conflict of interest.

\section{ACKNOWLEDGEMENTS}

Our own research work has been supported by grants from the National Health and Medical Research Council (APP631402, APP455890), The Cancer Council of Queensland, Australian Research Council (DP0985215) and Griffith University. RS is supported by an Endeavor Award.

\section{REFERENCES}

[1] Novina CD, Murray MF, Dykxhoorn DM, et al. siRNA-directed inhibition of HIV-1 infection. Nat Med 2002; 8(7): 681-6.

[2] Ghildiyal M, Zamore PD. Small silencing RNAs: an expanding universe. Nat Rev Genet 2009; 10(2): 94-108.

[3] Napoli C, Lemieux C, Jorgensen R. Introduction of a Chimeric Chalcone Synthase Gene into Petunia Results in Reversible CoSuppression of Homologous Genes in trans. Plant Cell 1990; 2(4): 279-89. 
[4] Fire A, Xu S, Montgomery MK, Kostas SA, Driver SE, Mello CC. Potent and specific genetic interference by double-stranded RNA in Caenorhabditis elegans. Nature 1998; 391(6669): 806-11.

[5] Elbashir SM, Lendeckel W, Tuschl T. RNA interference is mediated by 21 - and 22-nucleotide RNAs. Genes Dev 2001; 15(2): 188-200.

[6] Behlke MA. Chemical modification of siRNAs for in vivo use. Oligonucleotides 2008; 18(4): 305-19.

[7] Elbashir SM, Harborth J, Lendeckel W, Yalcin A, Weber K, Tuschl T. Duplexes of 21-nucleotide RNAs mediate RNA interference in cultured mammalian cells. Nature 2001; 411(6836): 494-8.

[8] Hammond SM, Bernstein E, Beach D, Hannon GJ. An RNAdirected nuclease mediates post-transcriptional gene silencing in Drosophila cells. Nature 2000; 404(6775): 293-6.

[9] Liu J, Carmell MA, Rivas FV, et al. Argonaute2 is the catalytic engine of mammalian RNAi. Science 2004; 305(5689): 1437-41.

[10] Boshart M, Gissmann L, Ikenberg H, Kleinheinz A, Scheurlen W, zur Hausen H. A new type of papillomavirus DNA, its presence in genital cancer biopsies and in cell lines derived from cervical cancer. EMBO J 1984; 3(5): 1151-7.

[11] Durst M, Gissmann L, Ikenberg H, zur Hausen H. A papillomavirus DNA from a cervical carcinoma and its prevalence in cancer biopsy samples from different geographic regions. Proc Natl Acad Sci USA 1983; 80(12): 3812-5. Epub 1983/06/01.

[12] Walboomers JM, Jacobs MV, Manos MM, et al. Human papillomavirus is a necessary cause of invasive cervical cancer worldwide. J Pathol 1999; 189(1): 12-9.

[13] Crum CP, McLachlin CM, Tate JE, Mutter GL. Pathobiology of vulvar squamous neoplasia. Curr Opin Obstet Gynecol 1997; 9(1): 63-9.

[14] Giuliano AR, Tortolero-Luna G, Ferrer E, et al. Epidemiology of human papillomavirus infection in men, cancers other than cervical and benign conditions. Vaccine 2008; 26(Suppl 10): K17-28.

[15] Campo MS. Papillomavirus and disease in humans and animals. Vet Comp Oncol. 2003; 1(1): 3-14.

[16] Schiffman M, Castle PE, Jeronimo J, Rodriguez AC, Wacholder S. Human papillomavirus and cervical cancer. Lancet 2007; 370(9590): 890-907.

[17] Baker CC, Phelps WC, Lindgren V, Braun MJ, Gonda MA, Howley PM. Structural and transcriptional analysis of human papillomavirus type 16 sequences in cervical carcinoma cell lines. J Virol 1987; 61(4): 962-71.

[18] von Knebel Doeberitz M, Rittmuller C, zur Hausen H, Durst M. Inhibition of tumorigenicity of cervical cancer cells in nude mice by HPV E6-E7 anti-sense RNA. Int J Cancer 1992; 51(5): 831-4.

[19] Stacey SN, Jordan D, Snijders PJ, Mackett M, Walboomers JM, Arrand JR. Translation of the human papillomavirus type 16 E7 oncoprotein from bicistronic mRNA is independent of splicing events within the E6 open reading frame. J Virol 1995; 69(11): 7023-31.

[20] Oh JM, Kim SH, Cho EA, Song YS, Kim WH, Juhnn YS. Human papillomavirus type 16 E5 protein inhibits hydrogen-peroxideinduced apoptosis by stimulating ubiquitin-proteasome-mediated degradation of Bax in human cervical cancer cells. Carcinogenesis 2010; 31(3): 402-10.

[21] Jiang M, Milner J. Selective Silencing of viral gene expression in HPV-positive human cervical carcinoma cells treated with siRNA, a primer of RNA interference. Oncogene 2002; 21: 6041-8.

[22] Schneider-Gädicke A, Schwarz E. Different human cervical carcinoma cell lines show similar transcription patterns of human papillomavirus type 18 early genes. EMBO J 1986; 5(9): 2285-92.

[23] Smotkin D, Prokoph H, Wettstein FO. Oncogenic and nononcogenic human genital papillomaviruses generate the E7 mRNA by different mechanisms. J Virol 1989; 63(3): 1441-7.

[24] Butz K, Ristriani T, Hengstermann A, Denk C, Scheffner M, Hoppe-Seyler F. siRNA targeting of the viral E6 oncogene efficiently kills human papillomavirus-positive cancer cells. Oncogene 2003; 22(38): 5938-45.

[25] Yamato K, Fen J, Kobuchi H, et al. Induction of cell death in human papillomavirus 18-positive cervical cancer cells by E6 siRNA. Cancer Gene Ther 2005; 13(3): 234-41.

[26] Putral LN, Bywater MJ, Gu W, et al. RNA interference against human papillomavirus oncogenes in cervical cancer cells results in increased sensitivity to cisplatin. Mol Pharmacol 2005; 68(5): 1311-9.
Yoshinouchi M, Yamada T, Kizaki M, et al. In vitro and in vivo growth suppression of human papillomavirus 16-positive cervical cancer cells by E6 siRNA. Mol Ther 2003; 8(5): 762-8.

[28] Gu W, Putral LN, Irving A, McMillan NA. Development and Future of oligo-based therapies for cervical cancer. Curr Opin Mol Ther 2007; 2: 126-31.

[29] Khairuddin N, Gantier MP, Blake SJ, et al. siRNA-induced immunostimulation through TLR7 promotes antitumoral activity against HPV-driven tumors in vivo. Immunol Cell Biol 2012; 90(2): 187-96.

[30] Gu W, Putral L, Hengst K, et al. Inhibition of cervical cancer cell growth in vitro and in vivo with lentiviral-vector delivered short hairpin RNA targeting human papillomavirus E6 and E7 oncogenes. Cancer Gene Ther 2006; 13(11): 1023-32.

[31] Niu X-Y, Peng Z-L, Duan W-Q, Wang H, Wang P. Inhibition of HPV 16 E6 oncogene expression by RNA interference in vitro and in vivo. Int J Gynecol Cancer 2006; 16: 743-51.

[32] Wu SY, Singhania A, Burgess M, et al. Systemic delivery of E6/7 siRNA using novel lipidic particles and its application with cisplatin in cervical cancer mouse models. Gene Therapy 2011; 18(1): 14-22.

[33] Scheffner M, Werness BA, Huibregtse JM, Levine AJ, Howley PM. The E6 oncoprotein encoded by human papillomavirus types 16 and 18 promotes the degradation of p53. Cell 1990; 63(6): 112936.

[34] Hall AH, Alexander KA. RNA interference of human papillomavirus type $18 \mathrm{E} 6$ and E7 induces senescence in $\mathrm{HeLa}$ cells. J Virol 2003; 77(10): 6066-9.

[35] Goodwin EC, Yang E, Lee C, Lee H, DiMaio D, Hwang ES. Rapid induction of senescence in human cervical carcinoma cells. Proc Natl Acad Sci USA 2000; 97(20): 10978-83.

[36] Goodwin EC, DiMaio D. Repression of human papillomavirus oncogenes in HeLa cervical carcinoma cells causes the orderly reactivation of dormant tumor suppressor pathways. Proc Natl Acad Sci USA 2000; 97(23): 12513-8

[37] DeFilippis RA, Goodwin EC, Wu L, DiMaio D. Endogenous human papillomavirus e6 and e7 proteins differentially regulate proliferation, senescence, and apoptosis in hela cervical carcinoma cells. J Virol 2003; 77(2): 1551-63.

[38] Hengstermann A, Linares LK, Ciechanover A, Whitaker NJ, Scheffner M. Complete switch from Mdm2 to human papillomavirus E6-mediated degradation of p53 in cervical cancer cells. Proc Natl Acad Sci USA 2001; 98(3): 1218-23.

[39] Jackson S, Harwood C, Miranda Thomas, Banks La, Storey A. Role of Bak in UV-induced apoptosis in skin cancer and abrogation by HPV E6 proteins Genes and Development 2000; 14: 3065-73.

[40] Thomas M, Banks L. Inhibition of Bak-induced apoptosis by HPV18 E6. Oncogene 1998; 17(23): 2943-54.

[41] Glaunsinger BA, Lee SS, thomas M, Banks L, Javier R. Interactions of the PDZ-protein MAGI-1 with adenovirus E4-ORF1 and high-risk papillomavirus E6 oncoproteins. Oncogene 2000; 19(46): 5270-80

[42] Malanchi I, Caldeira S, Krützfeldt M, Giarre M, Alunni-Fabbroni M, Tommasino M. Identification of a novel activity of human papillomavirus type $16 \mathrm{E} 6$ protein in deregulating the G1/S transition. Oncogene 2002; 21(37): 5665-72.

[43] Munger K, Phelps WC, Bubb V, Howley PM, Schlegel R. The E6 and E7 genes of the human papillomavirus type 16 together are necessary and sufficient for transformation of primary human keratinocytes. J Virol 1989; 63(10): 4417-21.

[44] Boyer SN, Wazer DE, Band V. E7 protein of human papilloma virus-16 induces degradation of retinoblastoma protein through the ubiquitin-proteasome pathway. Cancer Res 1996; 56(20): 4620-4.

[45] Slebos RJ, Lee MH, Plunkett BS, et al. p53-dependent G1 arrest involves $\mathrm{pRb}$-related proteins and is disrupted by the human papillomavirus 16 E7 oncoprotein. Proc Natl Acad Sci USA 1994; 91(12): 5320-4.

[46] Zerfass-Thome K, Zwerschke W, Mannhardt B, Tindle R, Botz J, Jansen-Dürr P. Inactivation of the cdk inhibitor p27KIP1 by the human papillomavirus type 16 E7 oncoprotein. Oncogene. 1996; 13(11): 2323-30

[47] Funk JO, Waga S, Harry JB, Espling E, Stillman B, Galloway DA Inhibition of CDK activity and PCNA-dependent DNA replication by $\mathrm{p} 21$ is blocked by interaction with the HPV-16 E7 oncoprotein. Genes Dev 1997; 11(16): 2090-100. 
[48] Jones D, Munger K. Analysis of the p53-mediated G1 growth arrest pathway in cells expressing the human papillomavirus type $16 \mathrm{E} 7$ oncoprotein. J Virol 1997; 71(4): 2905-12.

[49] He W, Staples D, Smith C, Fisher C. Direct Activation of CyclinDependent Kinase 2 by Human Papillomavirus E7. J Virol 2003; 77(19): 10566-74.

[50] Burgers W, Blanchon L, Pradhan S, de Launoit Y, Kouzarides T, Fuks F. Viral oncoproteins target the DNA methyltransferases. Oncogene 2007; 26(11): 1650-5.

[51] Duensing S, Lee LY, Duensing A, et al. The human papillomavirus type 16 E6 and E7 oncoproteins cooperate to induce mitotic defects and genomic instability by uncoupling centrosome duplication from the cell division cycle. Proc Nat Aca Sci USA 2000; 97(18): 10002-7.

[52] Khairuddin N. RNAi Against Virally-Induced Disease. Brisbane: University of Queensland 2010

[53] Rincheval V, Renaud F, Lemaire C, et al. Bcl-2 can promote p53dependent senescence versus apoptosis without affecting the G1/S transition. Biochem Biophys Res Commun 2002; 298(2): 282-8.

[54] Schwarze SR, Fu VX, Desotelle JA, Kenowski MLa, Jarrard DF. The identification of senescence-specific genes during the induction of senescence in prostate cancer cells. Neoplasia 2005; 7(9): 816-23.

[55] Grasl-Kraupp B, Ruttkay-Nedecky B, Koudelka H, Bukowska K, Bursch W, Schulte-Hermann R. In situ detection of fragmented DNA (tunel assay) fails to discriminate among apoptosis, necrosis, and autolytic cell death: a cautionary note. Hepatology 1995; 21(5): $1465-8$.

[56] van Engeland M, Nieland LJW, Ramaekers FCS, Schutte B, Reutelingsperger CPM. Annexin V-Affinity assay: A review on an apoptosis detection system based on phosphatidylserine exposure. Cytometry 1998; 31(1): 1-9.

[57] Burnett JC, Rossi JJ. RNA-based therapeutics: current progress and future prospects. Chem Biol 2012; 19(1): 60-71.

[58] Koivusalo R, Hietanen S. The cytotoxicity of chemotherapy drugs varies in cervical cancer cells depending on the p53 status. Cancer Biol Ther 2004; 3(11): 1177-83.

[59] Decatris MP, Sundar S, O'Byrne KJ. Platinum-based chemotherapy in metastatic breast cancer: current status. Cancer Treat Rev 2004; 30: 53-81.

[60] Siddik ZH. Biochemical and molecular mechanisms of cisplatin resistance. Cancer Treat Res 2002; 112: 263-84.

[61] Jung HS, Erkin OC, Kwon MJ, et al. The synergistic therapeutic effect of cisplatin with Human papillomavirus E6/E7 short interfering RNA on cervical cancer cell lines in vitro and in vivo. Int J Cancer J Int du Cancer 2012; 130(8): 1925-36.

[62] Koivusalo R, Krausz E, Helenius H, Hietanen S. Chemotherapy compounds in cervical cancer cells primed by reconstitution of p53 function after short interfering RNA-mediated degradation of human papillomavirus 18 E6 mRNA: opposit effect of siRNA in combination with different drugs. Mol Pharmacol 2005; 68(2): $372-82$.

[63] Liu WL, Green N, Seymour LW, Stevenson M. Paclitaxel combined with siRNA targeting HPV16 oncogenes improves cytotoxicity for cervical carcinoma. Cancer Gene Ther 2009; 16: 764-75.

[64] Hougardy BMT, Maduro JH, van der Zee AGJ, et al. Proteasome inhibitor MG132 sensitizes HPV-positive human cervical cancer cells to rhTRAIL-induced apoptosis. Int J Cancer 2006; 118: 1892900

[65] Reesink-Peters N, Hougardy BMT, Van den Heuvel FAJ, et al. Death receptors and ligands in cervical carcinogenesis: an immunohistochemical study. Gynecol Oncol 2005; 96: 705-13.

[66] Tan S, Hougardy BM, Meersma GJ, et al. HPV16 E6 RNA Interference Enhances Cisplatin and Death Receptor-mediated Apoptosis in Human Cervical Carcinoma cells. Mole Pharmacol 2012;81(5): 701-9.

[67] Eaton S, Wiktor P, Thirstrup D, Lake D, Nagaraj VJ. Efficacy of TRAIL treatment against HPV16 infected cervical cancer cells undergoing senescence following siRNA knockdown of E6/E7 genes. Biochem Biophys Res Commun 2011; 405(1): 1-6.

[68] Lagrange M, Charbonnier S, Orfanoudakis G, et al. Binding of human papillomavirus 16 E6 to p53 and E6AP is impaired by monoclonal antibodies directed against the second zinc-binding domain of E6. J Gen Virol 2005; 86: 1001-7.
[69] Courtete J, Sibler AP, Zeder-Lutz G, et al. Suppression of cervical carcinoma cell growth by intracytoplasmic codelivery of antioncoprotein E6 antibody and small interfering RNA. Mol Cancer Ther 2007; 6(6): 1728-35.

[70] Hampson L, Kitchener H, Hampson IN. Specific HIV protease inhibitors inhibit the ability of HPV16 E6 to degrade p53 and selectively kill E6-dependent cervical carcinoma cells in vitro. Antiviral Ther 2006; 11(6): 813-25.

[71] Schang LM, Coccaro E, Lacasse JJ. Cdk inhibitory nucleoside analogs prevent transcription from viral genomes. Nucleosides Nucleotides Nucleic Acids 2005; 24: 829-37.

[72] Węsierska-Gądek J, Wandl S, Kramer MP, Pickem C, Krystof V, Hajek SB. Roscovitine up-regulates p53 protein and induces apoptosis in human HeLaS3 cervix carcinoma cells. J Cell Biochem 2008; 105(5): 1161-71.

[73] Beutner KR, Tyring SK, Trofatter KF, et al. Imiquimod, a PatientApplied Immune-Response Modifier for Treatment of External Genital Warts. Antimicrob Agents Chemother 1998; 42(4): 789-94.

[74] Gross G, Rogozinski T, Schöfer H, et al. Recombinant Interferon Beta Gel as an Adjuvant in the Treatment of Recurrent Genital Warts: Results of a Placebo-Controlled Double-Blind Study in 120 Patients. Dermatology 1998; 196(3): 330-4.

[75] Sledz CA, Holko M, de Veer MJ, Silverman RH, Williams BR. Activation of the interferon system by short-interfering RNAs. Nat Cell Biol 2003; 5(9): 834-9.

[76] Marques JT, Devosse T, Wang D, et al. A structural basis for discriminating between self and nonself double-stranded RNAs in mammalian cells. Nat Biotechnol 2006; 24(5): 559-65.

[77] Gil J, Garcia MA, Gomez-Puertas P, et al. TRAF family proteins link PKR with NF-kappa B activation. Mol Cell Biol 2004; 24(10): 4502-12.

[78] Kumar A, Yang YL, Flati V, et al. Deficient cytokine signaling in mouse embryo fibroblasts with a targeted deletion in the PKR gene: role of IRF-1 and NF-kappaB. EMBO J 1997; 16(2): 406-16.

[79] Garcia MA, Gil J, Ventoso I, et al. Impact of protein kinase PKR in cell biology: from antiviral to antiproliferative action. Microbiol Mol Biol Rev 2006; 70(4): 1032-60.

[80] Poeck H, Besch R, Maihoefer C, et al. 5[prime]-triphosphatesiRNA: turning gene silencing and Rig-I activation against melanoma. Nat Med 2008; 14(11): 1256-63.

[81] Yoneyama M, Mika Kikuchi, Takashi Natsukawa, et al. The RNA helicase RIG-I has an essential function in double-stranded RNAinduced innate antiviral responses. Nat Immunol 2004; 5: 730-7.

[82] Kalali BN, Kollisch G, Mages J, et al. Double-Stranded RNA Induces an Antiviral Defense Status in Epidermal Keratinocytes through TLR3-, PKR-, and MDA5/RIG-I-Mediated Differential Signaling. J Immunol 2008; 181(4): 2694-704.

[83] Kawai T, Akira S. The role of pattern-recognition receptors in innate immunity: update on Toll-like receptors. Nat Immunol 2010 11(5): 373-84

[84] Bell JK, Askins J, Hall PR, Davies DR, Segal DM. The dsRNA binding site of human Toll-like receptor 3. Proc Nat Acad Sci USA 2006; 103(23): 8792-7.

[85] Moynagh PN. TLR signalling and activation of IRFs: revisiting old friends from the NF-[kappa]B pathway. Trends Immunol 2005; 26(9): 469-76.

[86] Honda K, Yanai H, Negishi H, et al. IRF-7 is the master regulator of type-I interferon-dependent immune responses. Nature 2005 434(7034): 772-7.

[87] Sato M, Suemori H, Hata N, et al. Distinct and Essential Roles of Transcription Factors IRF-3 and IRF-7 in Response to Viruses for IFN-[alpha]/[beta] Gene Induction. Immunity 2000; 13(4): 539-48.

[88] Kawai T, Takahashi K, Sato S, et al. IPS-1, an adaptor triggering RIG-I- and Mda5-mediated type I interferon induction. Nat Immunol 2005; 6(10): 981-8.

[89] Janeway CA, Travers P, Walport M, Shlomchik MJ. Immunobiology (the immune system in health and disease). New York: Garland Science Publishing 2005.

[90] Le Bon A, Tough DF. Links between innate and adaptive immunity via type I interferon. Curr Opin Immunol 2002; 14(4): 432-6.

[91] Ablasser A, Poeck H, Anz D, et al. Selection of Molecular Structure and Delivery of RNA Oligonucleotides to Activate TLR7 versus TLR 8 and to Induce High Amounts of IL-12p70 in Primary Human Monocytes. J Immunol 2009; 182(11): 6824-33

[92] Hornung V, Guenthner-Biller M, Bourquin C, et al. Sequencespecific potent induction of IFN-[alpha] by short interfering RNA 
in plasmacytoid dendritic cells through TLR7. Nat Med 2005; 11(3): $263-70$

[93] Alexopoulou L, Holt AC, Medzhitov R, Flavell RA. Recognition of double-stranded RNA and activation of NF-[kappa]B by Toll-like receptor 3. Nature 2001; 413(6857): 732-8.

[94] Gantier MP, Tong S, Behlke MA, et al. TLR7 Is Involved in Sequence-Specific Sensing of Single-Stranded RNAs in Human Macrophages. J Immunol 2008; 180(4): 2117-24.

[95] Zamanian-Daryoush M, Marques JT, Gantier MP, et al. Determinants of Cytokine Induction by Small Interfering RNA in Human Peripheral Blood Mononuclear Cells. J Interferon Cytokine Res 2008; 28(4): 221-33.

[96] Gantier MP, Williams BRG. Monitoring innate immune recruitment by siRNAs in mammalian cells. In: Ichim W-PMaT, editor. Methods in Molecular Biology: RNA Interference: From Biology to Clinical Application Totowa NJ: Humana Press 2010; pp. 21-33.

[97] O'Neill LAJ, Bowie AG. The family of five: TIR-domaincontaining adaptors in Toll-like receptor signalling. Nat Rev Immunol 2007; 7(5): 353-64.

[98] Kortylewski M, Kujawski M, Herrmann A, et al. Toll-like receptor 9 activation of signal transducer and activator of transcription 3 constrains its agonist-based immunotherapy. Cancer Res 2009; 69(6): 2497-505.

[99] Gantier MP, Tong S, Behlke MA, et al. Rational Design of Immunostimulatory siRNAs. Mol Ther 2010; 18(4): 785-95.

[100] Heil F, Hemmi H, Hochrein H, et al. Species-Specific Recognition of Single-Stranded RNA via Toll-like Receptor 7 and 8. Science 2004; 303(5663): 1526-9.

[101] Kanzler H, Barrat FJ, Hessel EM, Coffman RL. Therapeutic targeting of innate immunity with Toll-like receptor agonists and antagonists. Nat Med 2007; 13(5): 552-9.

[102] Garland S. Imiquimod. Curr Opin Infect Dis 2003; 16(2): 85-9.

[103] Chen X-Z, Mao X-H, Zhu K-J, et al. Toll like receptor agonists augment HPV 11 E7-specific $\mathrm{T}$ cell responses by modulating monocyte-derived dendritic cells. Arch Dermatol Res 2010; 302(1): 57-65.

[104] Averett DR, Fletcher SP, Li W, Webber SE, Appleman JR. The pharmacology of endosomal TLR agonists in viral disease. Biochem Soc Trans 2007; 035(6): 1468-72.

[105] Gao K, Huang L. Nonviral methods for siRNA delivery. Mol Pharm 2009; 6(3): 651-8.

[106] Soutschek J, Akinc A, Bramlage B, et al. Therapeutic silencing of an endogenous gene by systemic administration of modified siRNAs. Nature 2004; 432(7014): 173-8.

[107] Watts JK, Deleavey GF, Damha MJ. Chemically modified siRNA: tools and applications. Drug Discov Today 2008; 13(19-20): 84255 .

[108] Cristofaro P, Ramratnam B. RNAi tackles a sexually transmitted disease. Nat Biotechnol 2006; 24(1): 48-9.

[109] Cone RA. Barrier properties of mucus. Adv Drug Deliv Rev 2009; 61(2): 75-85. Epub 2009/01/13.

[110] Kanazawa T, Takashima Y, Hirayama S, Okada H. Effects of menstrual cycle on gene transfection through mouse vagina for DNA vaccine. Int J Pharm 2008; 360(1-2): 164-70.

[111] Palliser D, Chowdhury D, Wang QY, et al. An siRNA-based microbicide protects mice from lethal herpes simplex virus 2 infection. Nature 2006; 439(7072): 89-94.

[112] Wu Y, Navarro F, Lal A, et al. Durable protection from Herpes Simplex Virus-2 transmission following intravaginal application of siRNAs targeting both a viral and host gene. Cell Host Microbe 2009; 5(1): 84-94.

[113] Zhang Y, Cristofaro P, Silbermann R, et al. Engineering mucosal RNA interference in vivo. Mol Ther 2006; 14(3): 336-42.
[114] Woodrow KA, Cu Y, Booth CJ, Saucier-Sawyer JK, Wood MJ, Saltzman WM. Intravaginal gene silencing using biodegradable polymer nanoparticles densely loaded with small-interfering RNA. Nat Mater 2009; 8(6): 526-33.

[115] Wu SY, Chang HI, Burgess M, McMillan NA. Vaginal delivery of siRNA using a novel PEGylated lipoplex-entrapped alginate scaffold system. J Control Release 2011; 155(3): 418-26. Epub 2011/02/15.

[116] Khanna KV, Whaley KJ, Zeitlin L, et al. Vaginal transmission of cell-associated HIV-1 in the mouse is blocked by a topical, membrane-modifying agent. J Clin Investig 2002; 109(2): 205-11.

[117] Gillgrass AE, Ashkar AA, Rosenthal KL, Kaushic C. Prolonged exposure to progesterone prevents induction of protective mucosal responses following intravaginal immunization with attenuated herpes simplex virus type 2. J Virol 2003; 77(18): 9845-51.

[118] Kaushic C, Ashkar AA, Reid LA, Rosenthal KL. Progesterone increases susceptibility and decreases immune responses to genital herpes infection. J Virol 2003; 77(8): 4558-65.

[119] de la Fuente M, Csaba N, Garcia-Fuentes M, Alonso MJ. Nanoparticles as protein and gene carriers to mucosal surfaces. Nanomedicine (Lond) 2008; 3(6):845-57. Epub 2008/11/26.

[120] Mittal SK, Aggarwal N, Sailaja G, et al. Immunization with DNA, adenovirus or both in biodegradable alginate microspheres: effect of route of inoculation on immune response. Vaccine 2000; 19(23): 253-63.

[121] Krebs MD, Jeon O, Alsberg E. Localized and sustained delivery of silencing RNA from macroscopic biopolymer hydrogels. J Am Chem Soc 2009; 131(26): 9204-6.

[122] LeRoux MA, Guilak F, Setton LA. Compressive and shear properties of alginate gel: effects of sodium ions and alginate concentration. J Biomed Mater Res 1999; 47(1): 46-53.

[123] Jacobson GB, Gonzalez-Gonzalez E, Spitler R, et al. Biodegradable nanoparticles with sustained release of functional siRNA in skin. J Pharm Sci 2010; 99(10): 4261-6.

[124] Leachman SA, Hickerson RP, Schwartz ME, et al. First-in-human mutation-targeted siRNA phase $\mathrm{Ib}$ trial of an inherited skin disorder. Mol Ther 2010; 18(2): 442-6.

[125] Lobovkina T, Jacobson GB, Gonzalez-Gonzalez E, et al. In vivo sustained release of siRNA from solid lipid nanoparticles. ACS Nano 2011; 5(12): 9977-83.

[126] Lara MF, Gonzalez-Gonzalez E, Speaker TJ, et al. Inhibition of CD44 gene expression in human skin models using self-delivery siRNA administered by dissolvable microneedle arrays. Hum Gene Ther 2012; 23(8): 816-23

[127] Baldwin A, Grueneberg DA, Hellner K, et al. Kinase requirements in human cells: V. Synthetic lethal interactions between p53 and the protein kinases SGK2 and PAK3. Proc Natl Acad Sci USA 2010; 107(28): 12463-8.

[128] Baldwin A, Li W, Grace M, et al. Kinase requirements in human cells: II. Genetic interaction screens identify kinase requirements following HPV16 E7 expression in cancer cells. Proc Natl Acad Sci USA 2008; 105(43): 16478-83.

[129] Grueneberg DA, Degot S, Pearlberg J, et al. Kinase requirements in human cells: I. Comparing kinase requirements across various cell types. Proc Natl Acad Sci USA 2008; 105(43): 16472-7.

[130] Smith JA, White EA, Sowa ME, et al. Genome-wide siRNA screen identifies SMCX, EP400, and Brd4 as E2-dependent regulators of human papillomavirus oncogene expression. Proc Natl Acad Sci USA 2010; 107(8): 3752-7.

[131] Blake SJ, Bokhari FF, McMillan NA. RNA interference for viral infections. Curr Drug Targets 2012.

[132] Ambegia E, Ansell S, Cullis P, Heyes J, Palmer L, MacLachlan I. Stabilized plasmid-lipid particles containing PEG-diacylglycerols exhibit extended circulation lifetimes and tumor selective gene expression. Biochim Biophys Acta 2005; 1669(2): 155-63. 